\title{
Transplante de Células-Tronco Hematopoéticas em Doenças Reumáticas Parte 1: Experiếncia Internacional ${ }^{*}$
}

\section{Hematopoietic Stem Cell Transplantation for Rheumatic Diseases Part 1: International Experience}

\author{
Júlio C. Voltarelli( ${ }^{(1)}$, Ana Beatriz P. L. Stracieri ${ }^{(2)}$, Maria Carolina B. Oliveira ${ }^{(2,3)}$, Dannielle F. Godoi ${ }^{(3)}$, Daniela
} A. Moraes ${ }^{(3,4)}$, Fabiano Pieroni ${ }^{(2)}$, Kelen C. R. Malmegrim ${ }^{(4)}$, Marina A. Coutinho( ${ }^{(2)}$, Belinda P. Simões ${ }^{(5)}$

\begin{abstract}
RESUMO
Nesta revisão, discutem-se os resultados dos transplantes de célulastronco hematopoéticas (TCTH) para doenças reumáticas graves e refratárias à terapia convencional realizados no exterior. Revêemse brevemente as bases clínicas e experimentais para a realização desses transplantes e os resultados internacionais obtidos em lúpus eritematoso sistêmico (LES) (33/50 remissões completas no registro europeu, com dez recidivas posteriores e 12 óbitos; 41/45 remissões duradouras em um centro americano, com dois óbitos pósmobilização e quatro óbitos pós-transplante), artrite reumatóide (AR) do adulto $(58 / 73$ remissões parciais com $85 \%$ de recidivas posteriores e apenas um óbito no registro europeu), artrite idiopática juvenil (AIJ) (18/34 remissões duradouras e cinco óbitos no registro europeu), esclerose sistêmica (ES) (46/50 respostas em um estudo europeu multicêntrico, com $35 \%$ de recidivas e $23 \%$ de mortalidade, enquanto num estudo americano, houve quatro óbitos e duas pneumopatias progressivas dentre 19 pacientes e melhora cutânea e da qualidade de vida em todos os sobreviventes) e em uma miscelânea de outras doenças, incluindo as vasculites ( $9 / 15$ respostas completas no registro europeu). Conclui-se que, na experiência internacional, o TCTH autólogo induz remissões prolongadas na maioria das doenças graves e refratárias em que foi utilizado, com exceção da AR do adulto, justificando o início de estudos prospectivos randomizados comparando-o com a terapia convencional otimizada.
\end{abstract}

Palavras-chave: células-tronco hematopoéticas, transplante de medula óssea, doenças reumáticas.
In this review, we discuss the results of hematopoietic stem cell transplantation (HSCT) for severe and refractory rheumatic diseases performed abroad. We briefly review clinical and experimental basis for those transplants and the international results obtained in systemic lupus erythematosus (SLE) (33/50 complete remissions in the European registry with 10 relapses and 12 deaths, and 41 durable remissions in an American study with 2 deaths post-mobilisation and 4 deaths posttransplantation), adult rheumatoid arthritis (58/73 partial remissions with $85 \%$ of relapses and only one death in the European registry), juvenile idiopathic arthritis (18/34 durable remissions and 5 deaths in the European registry), systemic sclerosis (SSc) (46/50 responders in a multicentric European study with 35\% of relapses and 23\% of mortality, while in an US series, 4/19 patients died, 2 had progressive lung disease and all the survivors improved the skin scores and quality of life) and several other diseases, including vasculidities (9/15 complete responses in the European registry). We conclude that in the international experience, autologous HSCT induces sustained remission in most severe and refractory rheumatic diseases except for adult rheumatoid arthritis, and this finding justifies starting prospective randomized trials of HSCT compared to optimal conventional therapy.

Keywords: hematopoietic stem cells, bone marrow transplantation, rheumatic diseases.

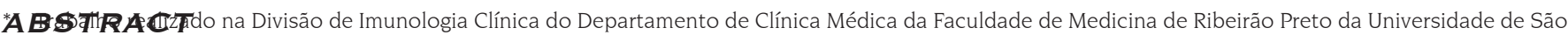
Paulo (FMRP-USP), Ribeirão Preto, SP, Brasil. Recebido em 24/1 1/2003. Aprovado, após revisão, em 6/4/2005.

1. Professor Titular e Chefe da Divisão de Imunologia Clínica do Departamento de Clínica Médica da Faculdade de Medicina de Ribeirão Preto da Universidade de São Paulo (FMRP-USP) e Coordenador da Unidade de Transplante de Medula Óssea (UTMO) do Hospital das Clínicas (HC) da FMRP-USP.

2. Médica Assistente da UTMO-HCFMRP-USP.

3. Pós-graduanda da FMRP-USP.

4. Médica bolsista da UTMO-HC-FMRP-USP.

5. Professora Doutora da Divisão de Hematologia da FMRP-USP.
}

Endereço para correspondência: Prof. Dr. Júlio C. Voltarelli. Hemocentro Regional, Campus-USP, CEP 14051-140. Ribeirão Preto, SP, Brasil. Tel. (16) $2101-9369$, fax 0162101-9309, E-mail: jcvoltar@fmrp.usp.br 


\section{INTRODUÇÃO}

As doenças auto-imunes (DAIs) apresentam um amplo espectro de manifestações clínico-laboratoriais. Em um extremo, há as doenças localizadas, associadas a lesões e auto-reatividade órgão-específica, como as endocrinopatias auto-imunes (tireoidite de Hashimoto, tireotoxicose de Graves, diabetes insulino-dependente, insuficiência adrenal de Addison, hipogonadismo, poliendocrinopatia auto-imune), anemia perniciosa e a gastrite atrófica. Com a notável exceção do diabetes tipo I, a maioria dessas doenças remite facilmente com o tratamento dirigido ao distúrbio hormonal ou nutricional subjacente. No outro extremo, encontram-se as doenças multissistêmicas, associadas a auto-reatividade humoral e celular de ampla distribuição e/ou imunocomplexos circulantes, originando enfermidades reumáticas, como a artrite reumatóide (AR), o lúpus eritematoso sistêmico (LES), a febre reumática, a esclerose sistêmica (ES), a dermatopolimiosite (DPM) e as vasculites primárias. Elas podem afetar órgãos vitais e causar significativa morbi-mortalidade, sendo tratadas com antiinflamatórios, imunomoduladores ou imunossupressores inespecíficos. Em uma região intermediária deste espectro, existem outras DAIs, como a esclerose múltipla, a miastenia gravis, os pênfigos e as citopenias auto-imunes, que afetam apenas um sistema orgânico, mas, pela extensão de seu acometimento, têm conseqüências semelhantes às das DAIs sistêmicas, sendo, em geral, tratadas da mesma maneira.

Embora tenha havido grandes progressos no entendimento dos mecanismos imunológicos envolvidos nas DAIs, a etiologia da grande maioria delas permanece desconhecida, limitando o desenvolvimento de terapêuticas específicas. Uma exceção ilustrativa desta realidade é a DAI associada à infecção estreptocócica do grupo A, em que tanto a febre reumática como a glomerulonefrite difusa aguda podem ser facilmente prevenidas pelo tratamento precoce ou profilaxia da infecção desencadeante. Os avanços inegáveis na terapêutica farmacobiológica das DAIs sistêmicas, que ocorreram recentemente, não impediram que uma subpopulação de pacientes com formas progressivas dessas doenças e refratárias à terapia convencional tivesse um mau prognóstico, semelhante ao de muitas doenças neoplásicas ${ }^{(1)}$. A baixa qualidade e expectativa de vida desses pacientes justifica o emprego de terapias bastante agressivas, como a quimioterapia, imunoterapia e/ou radioterapia em altas doses, com ou sem transplante de célulastronco hematopoéticas (TCTH).

\section{BASES CIENTÍFICAS PARA O TRATAMENTO DE DOENÇAS AUTO-IMUNES COM TRANSPLANTE DE CÉLULAS-TRONCO HEMATOPOÉTICAS}

Nos últimos oito anos, foram desenvolvidos vários protocolos de tratamento de DAIs graves e refratárias com imunossupressão intensa ou imunoablação, seguida de resgate com células-tronco hematopoéticas (CTH) autólogas ou alogênicas, baseando-se em um conjunto de evidências científicas de ordem clínica e experimental (Tabela 1): 1) prevenção ou cura de DAI por TCTH em modelos experimentais ${ }^{(2-4)}$; 2) transferência de DAI por TCTH alogênico em humanos ${ }^{(5)}$; 3) efeito benéfico do transplante em dezenas de casos de concomitância de doenças hematológicas e auto-imunes ${ }^{(5-7)}$; e 4) em centenas de casos de TCTH em DAIs isoladas ${ }^{(5,8-13)}$. A primeira evidência clínica do possível benefício da imunossupressão maciça sobre a evolução de DAI grave não associada a hemopatias foi publicada em 1993, sendo o relato de uma paciente acometida de crioglobulinemia mista com nefrite e vasculite, que obteve remissão prolongada após quimioterapia em altas doses sem infusão de $\mathrm{CTH}^{(14)}$ e não. Resultados semelhantes têm sido relatados pelo grupo da Johns Hopkins University (Baltimore, EUA) no LES e em outras DAIs, utilizando doses imunoablativas de ciclofosfamida (CY, 200 $\mathrm{mg} / \mathrm{kg}$ ) sem resgate de $\mathrm{CTH}^{(15,16)}$. Entretanto, este esquema produz um período relativamente prolongado de pancitopenia (média de 14 dias, variando de 11 a 22 dias no LES) e foi associado a significativa mortalidade quando aplicado à anemia aplástica no National Institutes of Health $(N I H)$ americano ${ }^{(17)}$, levando à interrupção do protocolo.

Baseando-se nas evidências apontadas acima, vários centros começaram a transplantar pacientes portadores de DAIs isoladas, graves e refratárias à terapia convencional, com CTH autólogas, depletadas in vivo ou in vitro de linfócitos $\mathrm{T}$ e/ou B. O primeiro caso publicado, em outubro de 1996(18), foi o de uma síndrome "CREST-like" com hipertensão pulmonar, cujo transplante foi realizado na Basiléia, Suíça, enquanto o primeiro paciente com LES foi transplantado em Gênova em fevereiro de 1996, sendo o respectivo relato de caso publicado em meados de $1997 \mathrm{e}$ o seguimento atualizado em $2001^{(19)}$. No Brasil, o transplante realizado no Hospital Albert Einstein, SP, com CTH não-manipuladas, em uma paciente com crioglobulinemia, anemia hemolítica e vasculite, em abril de 1996, foi um dos primeiros a serem realizados no mundo em DAI isolada, mas, infelizmente, foi relatado apenas em um evento científico nacional ${ }^{(20)}$. 
TABELA 1

EVIDÊNCIAS EXPERIMENTAIS E CLÍNICAS PARA O USO DE TRANSPLANTE DE CÉLULAS-TRONCO HEMATOPOÉTICAS (TCHC) NO TRATAMENTO DE DOENÇAS AUTO-IMUNES (DAIS)

\begin{tabular}{|c|c|c|}
\hline Categoria & Evidência & Referência(s) \\
\hline $\begin{array}{l}\text { Modelos animais de DAIs geneticamente determinadas: } \\
\text { camundongos NZB/W, MRL/lpr, BXSB (LES), NOD } \\
\text { (diabetes tipo I), NZB/KN (artrite reumatóide), SCG/Kj } \\
\text { (poliarterite nodosa) }\end{array}$ & $\begin{array}{l}\text { Prevenção e/ou cura da DAI por } \\
\text { transplante alogênico de medula óssea }\end{array}$ & 3,4 \\
\hline $\begin{array}{l}\text { Modelos animais de DAIs induzidas por antígenos: } \\
\text { encefalomielite auto-imune experimental, artrite } \\
\text { por adjuvante, miastenia gravis }\end{array}$ & $\begin{array}{l}\text { Prevenção e/ou cura da DAI por transplante alogênico, } \\
\text { singênico ou autólogo de medula óssea }\end{array}$ & 2 \\
\hline Transferência de doenças ou manifestações auto-imunes por TCTH & $\begin{array}{l}\text { DAIs predominantemente órgão-específicas podem ser } \\
\text { transferidas do doador ao receptor }\end{array}$ & 5 \\
\hline DAI concomitante a hemopatia submetida a TCTH alogênico & $\begin{array}{l}\text { Maioria das DAIs tem remissão prolongada, associada a } \\
\text { DECH aguda e/ou crônica }\end{array}$ & $\begin{array}{l}5-7,44 \\
68,68 a\end{array}$ \\
\hline DAI concomitante a hemopatia submetida a TCTH autólogo & Maioria das DAIs tem remissão curta & $5,6,9-11$ \\
\hline DAI isolada submetida a imunoablação sem TCTH & $\begin{array}{l}\text { Maioria das DAIs tem remissão prolongada, mas com } \\
\text { longo período neutropênico }\end{array}$ & $14-16$ \\
\hline $\begin{array}{l}\text { DAI isolada submetida a imunoablação com TCTH autólogo } \\
\text { ou singênico }\end{array}$ & $\begin{array}{l}\text { Maioria das DAIs tem remissão ou estabilização, mas } \\
\text { com ocorrência de recaídas }\end{array}$ & $5,8-13$ \\
\hline DAI isolada submetida a imunoablação com TCTH alogênico & $\begin{array}{l}\text { Usado em poucos casos (citopenias } \\
\text { hematológicas, AR, ES), } \\
\text { com remissão longa }\end{array}$ & $\begin{array}{l}21,27,28,43, \\
56,61,67,71, \\
73,80\end{array}$ \\
\hline
\end{tabular}

DECH: doença do enxerto-contra-hospedeiro

A maioria dos pacientes com doenças reumáticas recebeu transplante autólogo de CTH, que são mobilizadas da medula óssea para o sangue periférico com ciclofosfamida seguida de fator de crescimento granulocitário (G-CSF), coletadas por leucocitaférese, selecionadas positivamente $\left(\mathrm{CD} 34^{+}\right)$em colunas de afinidade comerciais e congeladas em nitrogênio líquido. Os regimes de condicionamento (imunossupressão pré-transplante) variaram de acordo com a doença de base. A maioria deles inclui ciclofosfamida e globulina antitimocitária (ATG - antithymocyte globulin), mas alguns grupos americanos utilizam a irradiação corporal total (TBI - total body irradiation), principalmente para esclerose sistêmica e AR. A Tabela 2 resume as principais etapas do TCTH autólogo para doenças reumáticas: seleção dos pacientes, mobilização e criopreservação das CTH, condicionamento, infusão das CTH e seguimento pós-transplante imediato e tardio. Outra abordagem em investigação é o uso de CTH alogênicas (da medula óssea, sangue periférico mobilizado ou cordão umbilical), obtidas de doadores familiares ou voluntários e infundidas após um regime de condicionamento semelhante ao utilizado nos TCTH autólogos, com características imunoablativas, mas sem produzir mieloablação, o que reduz a morbi-mortalidade em relação ao TMO alogênico convencional. Esses transplantes, empregados crescentemente em onco-hematologia, são chamados de TCTH não-mieloablativos, submieloablativos, subablativos ou, simplesmente, "mini-alo" transplantes $^{(21)}$. Têm a vantagem de induzir o efeito enxertocontra-auto-imunidade, propiciando a eliminação de clones linfocitários auto-reativos pela reação alogênica ${ }^{(6)}$, a qual, por outro lado, pode lesar tecidos normais e causar a reação do enxerto-contra-hospedeiro, produzindo significativa morbi-mortalidade.

Várias revisões sobre o uso de TCTH em DAI foram publicadas nos últimos anos ${ }^{(5,8-13)}$, inclusive analisando a experiência brasileira, isoladamente ${ }^{(22)}$ ou combinada com a chinesa ${ }^{(23)}$, pois o Brasil e a China são os principais países em desenvolvimento com programas de TCTH para DAI. Nesta revisão, dividida em duas partes, são analisados, primeiramente, os resultados clínicos dos TCTH para doenças reumáticas realizados no exterior e, posteriormente, os realizado no Brasil e serão discutidas as perspectivas futuras de evolução nesta área. Os transplantes para esclerose múltipla, apesar de constituírem os mais numerosos feitos para DAI ${ }^{(8,10,11,12)}$, inclusive no Brasil ${ }^{(22,23)}$, não serão incluídos nesta análise, restrita às doenças reumáticas. 
FASES DO TRANSPLANTE DE CÉLULAS-TRONCO HEMATOPOÉTICAS (TCTH) AUTÓLOGAS PARA DOENÇAS REUMÁTICAS EM ESTUDOS-PILOTO

\begin{tabular}{ll}
\hline Fase & Características \\
\hline Seleção dos pacientes & $\begin{array}{l}\text { Critérios de inclusão: formas graves de doenças reumáticas refratárias à melhor terapêutica } \\
\text { medicamentosa disponível } \\
\text { Critérios de exclusão: disfunção orgânica que comprometa tolerância ao condicionamento (a não ser } \\
\text { que a disfunção seja causada pela própria doença, recente e possa ser revertida pelo transplante) }\end{array}$ \\
\hline Mobilização das CTH & $\begin{array}{l}\text { Pode ser feita por fator de crescimento mielóide (G- ou GM-CSF) isolado ou combinado com quimioterapia, } \\
\left.\text { geralmente ciclofosfamida (2 ou } 4 \mathrm{~g} / \mathrm{m}^{2}\right) \text {. No primeiro caso, há maior chance de piora da doença e, no } \\
\text { segundo, de melhora da mesma, mas também de toxicidade pela quimioterapia. As CTH são }\end{array}$ \\
coletadas por leucocitaférese e criopreservadas até a infusão \\
Condicionamento & $\begin{array}{l}\text { Existem vários esquemas imunoablativos, empregando ou não irradiação corporal total. A maioria deles } \\
\text { inclui ciclofosfamida (200 mg/kg) e anticorpos policlonais contra células T- ATG (de cavalo ou de coelho) }\end{array}$ \\
\hline Manipulação e infusão das CTH & $\begin{array}{l}\text { No exterior, a maioria dos protocolos usa células CD34 selecionadas in vitro; quando isto não é feito, } \\
\text { recomenda-se a depleção in vivo das células T do enxerto com ATG }\end{array}$ \\
Seguimento pós-transplante & $\begin{array}{l}\text { paciente recebe profilaxia anti-microbiana e suporte para pancitopenia; é monitorizado para as } \\
\text { complicações do transplante e para as manifestações da doença básica }\end{array}$ \\
\hline imediato e tardio &
\end{tabular}

\section{RESULTADOS CLÍNICOS DE TCTH PARA DOENÇAS REUMÁTICAS ISOLADAS}

Cerca de 800 transplantes de células-tronco hematopoéticas para doenças auto-imunes isoladas, não associadas a hemopatias, foram realizados no mundo, principalmente na Europa, Austrália e EUA, mas também na Ásia e no Brasil. $\mathrm{O}$ registro europeu, patrocinado pelo EBMT/EULAR e centralizado na Basiléia, Suíça, possuía, até outubro de 2004, 536 casos relatados por 110 centros em 21 países, incluindo Austrália, Japão e China e incluindo 311 pacientes com doenças reumáticas. Inicialmente, esses casos eram submetidos a uma análise clínica qualitativa baseada nos relatórios médicos de seguimento, que era publicada nas várias revisões do grupo europeu ${ }^{(5,8-11 \mathrm{a}, \mathrm{b})}$. Posteriormente, foram publicados separadamente os resultados de séries de casos de transplante agrupadas por doenças, em que a evolução clínica era definida de modo mais rigoroso ${ }^{(24,37,51,58,65)}$ (Tabela 3). Nos Estados Unidos, as maiores casuísticas provêm de estudos centralizados na Northwestern University (NWU), em Chicago, sob a liderança do Dr. Richard Burt, e no Fred Hutchinson Cancer Research Center (FHCRC), em Seattle, com os Drs. Richard Nash e Peter McSweeney. Como mencionado acima, a mobilização das CTH da medula óssea geralmente é feita com ciclofosfamida seguida de G-CSF, enquanto o condicionamento varia de acordo com a doença de base, a qual servirá de referência para a revisão dos resultados iniciais desses transplantes.

\section{LÚPUS ERITEMATOSO SISTÊMICO}

O grupo europeu publicou recentemente sua experiência com TCTH para LES em 53 pacientes, que apresentavam uma mediana de sete critérios diagnósticos do Colégio Americano de Reumatologia (ACR) e nefrite lúpica em $62 \%$ dos casos. Ocorreram sete óbitos (13\%) por toxicidade do transplante, quatro por progressão da doença $(7,5 \%)$ e um por causa não-relacionada (suicídio). A mortalidade foi associada a maior duração da doença pré-transplante. Observou-se remissão da doença em 66\% dos pacientes avaliáveis $(33 / 50)$, dos quais 32\% (10/31) recaíram posteriormente. A recaída foi associada com a ausência de anticorpo anti-DNA nativo antes do transplante $\left.{ }^{(24}\right)$. O grupo de Gênova, liderado por Alberto Marmont, pioneiro no TCTH para LES, relatou dois casos ilustrativos, em que houve reativação da doença três anos e seis meses após o transplante, sendo controlada com imunossupressão convencional, o que não ocorria antes do transplante ${ }^{(19)}$. Evolução semelhante foi observada em dois pacientes, que recaíram 30 e 40 meses após o transplante, na experiência da Northwestern University (NWU) de Chicago com transplante autólogo de CTH selecionadas in vitro, em 15 pacientes com LES refratário à terapia convencional ${ }^{(25)}$. Desses pacientes, oito apresentavam nefrite lúpica como indicação principal do transplante, quatro cerebrite, um pneumonite e dois doença abdominal (peritonite ou vasculite mesentérica). A mobilização foi feita com ciclofosfamida $2 \mathrm{~g} / \mathrm{m}^{2}$ e G-CSF e o condicionamento incluiu ciclo- 
TABELA 3

RESUlTAdOS CLÍNICOS PUBLICAdOS DE TCTH PARA DOENCAS REUMÁTICAS EM ESTUDOS-PILOTO REALIZADOS NO EXTERIOR EM SÉRIES PUBLICADAS COM UM NÚMERO RAZOÁvEL DE PACIENTES $(>15)$

\begin{tabular}{|c|c|c|c|c|c|c|c|c|c|c|}
\hline \multirow[t]{2}{*}{ Doença } & \multirow[t]{2}{*}{ Centro } & \multirow[t]{2}{*}{$\mathrm{N}$} & \multirow{2}{*}{$\begin{array}{l}\text { Condicionamento e tipo de } \\
\text { CTH predominante }\end{array}$} & \multirow{2}{*}{$\begin{array}{c}\text { Seg } \\
\text { (meses) }\end{array}$} & \multicolumn{4}{|c|}{ Resposta Clínica } & \multicolumn{2}{|c|}{ Óbitos } \\
\hline & & & & & $\mathrm{RC}$ & $\mathrm{RP}$ & NR & REC & TRM & Progr \\
\hline $\operatorname{LES}^{(24)}$ & $\begin{array}{l}\text { EBMT/ } \\
\text { Eular }\end{array}$ & 53 & $\begin{array}{c}\text { CY+ATG } \\
\text { Seleção CD34 }\end{array}$ & $>6$ & 33 & 7 & 1 & 10 & 7 & 5 \\
\hline LES $^{(25)}$ & NWU & 17 & $\begin{array}{c}\text { CY+ATG } \\
\text { Seleção CD34 }\end{array}$ & $12-66$ & 9 & 6 & - & 2 & 2 & - \\
\hline $\operatorname{LES}^{(33)}$ & China & 18 & $\begin{array}{l}\text { CY+TLI+ATG } \\
\text { Sem seleção }\end{array}$ & $3-26$ & 12 & 3 & 3 & 2 & - & - \\
\hline$A R^{(37)}$ & $\begin{array}{l}\text { EBMT/ } \\
\text { ABMTR }\end{array}$ & 73 & $\begin{array}{c}C Y+T B I+A T G \\
T M O+T C D\end{array}$ & $3-55$ & 3 & 58 & 12 & 31 & 2 & - \\
\hline $\operatorname{AIJ}(50,51)$ & $\begin{array}{l}\text { EBMT/ } \\
\text { ABMTR }\end{array}$ & 34 & $\begin{array}{c}C Y+T B I+A T G \\
T M 0+T C D\end{array}$ & $8-60$ & 18 & 6 & $7 ?$ & 7 & 3 & 2 \\
\hline$E S^{(57)}$ & $\begin{array}{c}\text { EBMT/ } \\
\text { Eular }\end{array}$ & 37 & $\begin{array}{c}C Y \\
\text { CD34+ }\end{array}$ & $>3$ & 20 & 1 & 3 & 2 & 7 & 4 \\
\hline$E S^{(58)}$ & $\begin{array}{l}\text { EBMT/ } \\
\text { Eular }\end{array}$ & 57 & $\begin{array}{c}\text { CY } \\
\text { CD34+ }\end{array}$ & $>6$ & 14 & 32 & 4 & 16 & 5 & 8 \\
\hline $\mathrm{ES}^{(59)}$ & FHCRC & 19 & $\begin{array}{c}\text { TBI+CY+ATG } \\
\text { Seleção CD34 }\end{array}$ & $8-45$ & 12 & - & 3 & - & 3 & 1 \\
\hline
\end{tabular}

N: total de transplantes avaliáveis; Seg: seguimento (meses); RC: remissão completa; RP: remissão parcial; NR: não remissão ou ausência de resposta; REC: recaída; TRM: mortalidade relacionada ao transplante; Prog: mortalidade relacionada à progressão da doença básica; Eular: Liga Européia contra o Reumatismo; EBMT: Grupo Europeu de TM0; NWU: Northwestern University, Chicago; FHCRC: Fred Hutchinson Cancer Research Center, Seattle - EUA; ABMTR: Registro Internacional de Transplantes de Medula Óssea Autólogos; NIH: National Institutes of Health; BEAM: BCNU, etoposídio, aracytin e melfalan; CY: ciclofosfamida; ATG: globulina anti-timocitária; TBI: irradiação corporal total; TLI: irradiação linfóide total; TCD: depleção de células T

fosfamida (50 mg/kg x 4 dias) e ATG eqüina (30 mg/ $\mathrm{kg} / \mathrm{d}$ x 3 dias). Com exceção dos dois pacientes citados acima, todos os outros, seguidos por um tempo mínimo de 12 meses, obtiveram remissão sustentada da doença, mas seis deles ainda necessitavam de corticoesteróides ou cloroquina póstransplante (remissão parcial). Não foi registrado qualquer óbito nos pacientes submetidos a transplante, nesta série, mas cinco pacientes foram a óbito antes de serem transplantados. Dois deles sofreram complicações após a mobilização (cerebrite lúpica e mucormicose cerebral, respectivamente) e outros três, antes da mobilização (dois casos de sepse e um de miocardiopatia), refletindo a gravidade do estado clínico dos pacientes selecionados para transplante. A experiência da NWU foi ampliada, mais recentemente, para 45 pacientes, tendo ocorrido quatro óbitos entre 11 e 30 meses pós-transplante (três por recaída da doença e um por infecção), estando os outros pacientes em remissão da doença ${ }^{(25 a)}$. Nesta população de pacientes, a síndrome antifosfolípide (APS) estava presente em 61\% (28/46) dos pacientes (17\% APS provável e 44\% APS definida). Na maioria desses pacientes, os marcadores laboratoriais da APS desa- pareceram após o TCTH e em 18/22 deles que eram refratários à anticoagulação puderam interromper esta terapia quatro meses em média após o transplante, sem recorrência de fenômenos trombóticos ${ }^{(26)}$. O primeiro relato de desaparecimento do anticorpo antifosfolípide após TCTH foi feito em 1999, em um paciente assintomático que recebeu TMO alogênico para leucemia mielóide crônica $^{(27)}$. Mais recentemente, este fato foi observado em outros dois pacientes: 1) um afetado por SAF associada à síndrome de Evans (anemia hemolítica e trombocitopenia auto-imunes) foi submetido, na Suécia, a um TCTH alogênico de doador não-familiar (do banco de medula óssea), seguido de infusão de linfócitos do doador, para reforçar a reação alogênica. Um mês após a infusão e quatro meses após o transplante, as contagens sangüíneas e a função hemostática tinham se normalizado e o anticorpo antifosfolípide havia desaparecido $^{(28)}$; 2) outro paciente com SAF refratária, associada à necrose miocárdica, recebeu TCTH autólogo no Japão, obtendo remissão da doença ${ }^{(29)}$ (Tabela 4). Casos isolados de sucesso terapêutico do TCTH autólogo em pneumonite ${ }^{(30)}$ e cerebrite ${ }^{(31)}$ lúpicas refratárias foram também relatados. 


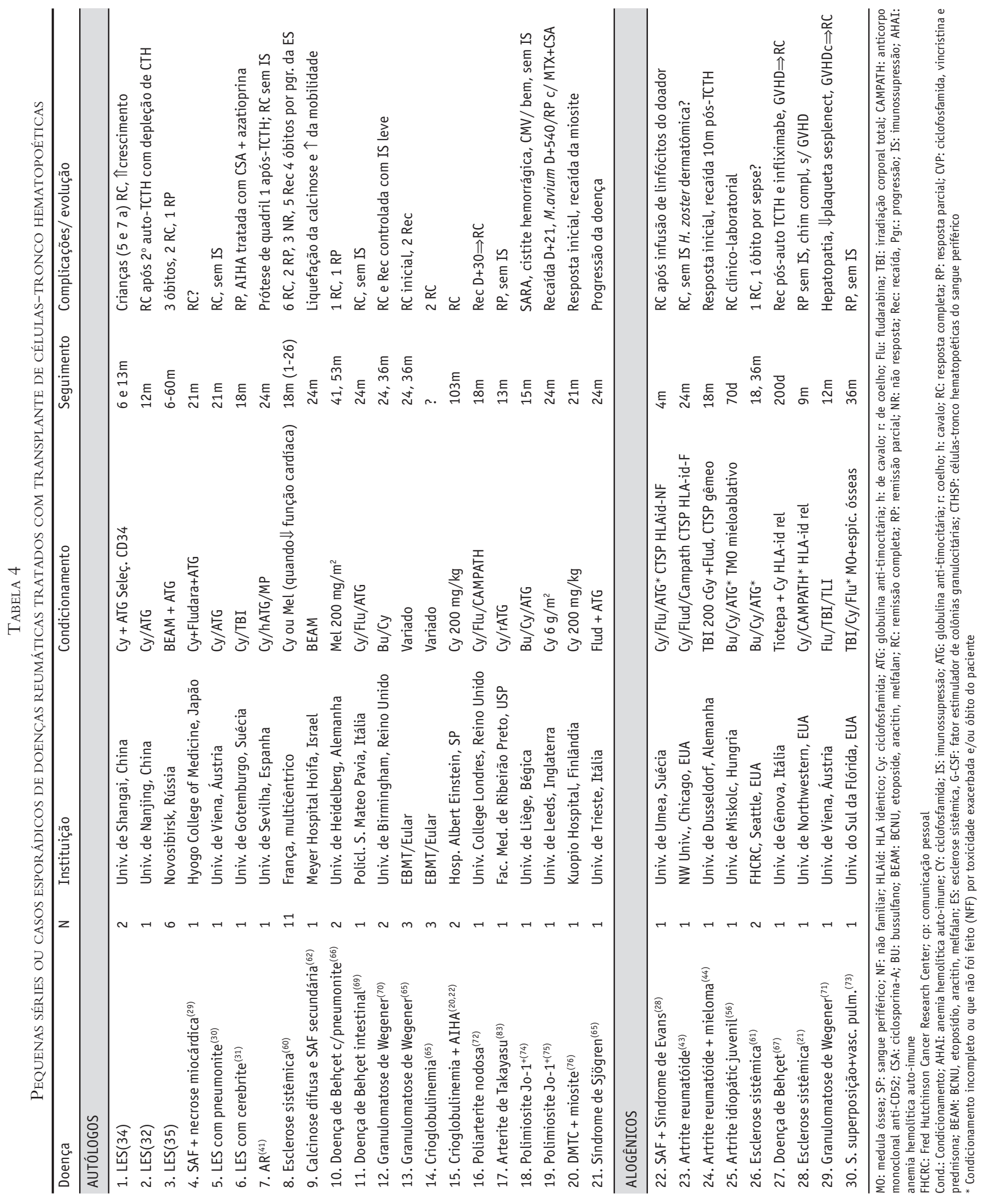


$\mathrm{Na}$ experiência chinesa, sete pacientes foram transplantados na Universidade de Nanjing, observando-se cinco remissões, uma progressão e um óbito ${ }^{(23)}$; um paciente transplantado inicialmente com CTHSP autólogas não-manipuladas obteve remissão com um segundo transplante autólogo com CTH selecionadas in vitro ${ }^{(32)}$. Por outro lado, o grupo de Zhengzhou transplantou 18 pacientes, observando-se 12 remissões completas, três parciais, três falhas terapêuticas e duas recaídas, mas nenhum óbito ${ }^{(33)} \mathrm{e}$ o grupo de Shangai relatou TCTH bem sucedido em duas crianças (de cinco e sete anos) portadoras de LES $^{(34)}$. Na experiência russa, dentre seis pacientes com LES condicionados com BEAM+ATG, ocorreram três óbitos por complicações do transplante, duas remissões completas e uma remissão $\operatorname{parcial}^{(35)}$.

O grupo europeu cogita iniciar um protocolo clínico de fase II, introduzindo tratamento de manutenção póstransplante (com azatioprina ou micofenolato mofetil MMS) para reduzir as recidivas, antes de iniciar estudos randomizados de fase $\operatorname{III}^{(10,11)}$ (Tyndall, comunicação pessoal). Por outro lado, os grupos americanos planejam estudos randomizados de fase III, comparando TCTH com o tratamento padrão (pulsos de ciclofosfamida endovenosa) para formas graves da doença, detectada em fases mais precoces de evolução ${ }^{(36)}$. Em uma segunda etapa, o TCTH seria comparado a formas mais inovadoras de imunossupressão, como MMS, rituximabe (anticorpo anti-células B) ou outros agentes biológicos, ou mesmo, com altas doses de ciclofosfamida sem resgate de $\mathrm{CTH}^{(16)}$.

\section{ARTRITE REUMATÓIDE DO ADULTO}

Recentemente, num estudo retrospectivo combinando dados de 76 pacientes dos registros europeu e americano (EBMT e ABMTR), três pacientes foram mobilizados, mas não transplantados e a mobilização exacerbou a atividade da doença em oito pacientes e reduziu a atividade em outros oito. Dos 73 pacientes transplantados, três tiveram resposta completa, 58 resposta parcial (ACR 20-70) e 12 não responderam; a maioria dos pacientes (85\%) apresentou atividade da doença pós-transplante, necessitando reintroduzir a terapêutica imunomoduladora e a metade deles respondeu a essa terapia ${ }^{(37)}$. Esta taxa de resposta em recaídas pós-transplante foi semelhante à obtida nos EUA (3/5) usando anticorpos anti-TNF em pacientes que recaíram pós-transplante e não haviam usado esses agentes previamente ${ }^{(38)}$. Maior frequiência de resposta $(9 / 10)$ foi obtida com o uso de rituximabe (anticorpo monoclonal antiCD20) em recidivas de AR pós-TCTH, mas seis pacientes voltaram a recidivar, sendo necessário novo tratamento com rituximabe em quatro pacientes ${ }^{(39)}$. Apesar desta alta taxa de recidiva após TCTH, demonstrou-se recentemente significativa redução da destruição osteoarticular, avaliada radiologicamente, após o transplante ${ }^{(39 a)}$, ao lado de um aumento dos índices de qualidade de vida ${ }^{(29 b)}$.

Em um paciente que respondeu dramaticamente ao TCTH em três meses, mas recaiu posteriormente, a atividade da doença correlacionou-se com a infiltração linfocítica sinovial, sem correspondência com a repopulação de linfócitos $\mathrm{T}$ no sangue periférico ${ }^{(40)}$, achados semelhantes aos encontrados mais recentemente em sete pacientes (cinco respondedores e dois não-respondedores ao TCTH $)^{(40 a)}$. Finalmente, uma paciente com AR em Sevilha, Espanha, foi submetida a prótese de quadril por necrose asséptica de cabeça de fêmur, um ano após TCTH autólogo e encontrase em remissão de ambas as doenças dois anos após o TCTH, mostrando que o TCTH prévio não contra-indica necessariamente a reconstrução cirúrgica do quadril na $\mathrm{AR}^{(41)}$.

$\mathrm{Na}$ experiência de Chicago, o condicionamento com ciclofosfamida associada à ATG aplicado à AR manteve remissão em apenas $2 / 4$ pacientes $^{(42)}$, levando o grupo a explorar regimes de condicionamento mais agressivos, incorporando irradiação corporal total ao transplante autólogo, e adotando transplantes alogênicos subablativos em pacientes com doadores compatíveis. O primeiro paciente submetido a este último tipo de transplante foi condicionado com ciclofosfamida, fludarabina e CAMPATH e obteve remissão em seguimento de dois anos ${ }^{(43)}$. Entretanto, um outro paciente que recebeu transplante submieloablativo para AR concomitante a mieloma múltiplo na Alemanha teve recidiva da doença articular dez meses após o transplante ${ }^{(44)}$. Outra estratégia para evitar recidivas, adotada no protocolo randomizado europeu (estudo ASTIRA) que usa CY+ATG no condicionamento, foi a introdução de imunossupressão em baixas doses (metotrexato 15 a $25 \mathrm{mg} / \mathrm{sem}$ ou leflunomida) logo após a enxertia, como terapia de manutenção ${ }^{(10)}$. Entretanto, apenas um paciente foi transplantado até agora neste protocolo, pois a maioria dos pacientes com AR grave está participando de protocolos clínicos com agentes biológicos (anti-TNF, anti-IL-6, IL-1RA outros) (Bingham, comunicação pessoal).

Quatro aspectos importantes do TCTH autólogo para DAI foram analisados na Austrália e na Europa em estudos controlados com pacientes afetados por AR: 1) No primeiro deles, a composição celular do enxerto mobilizado do sangue periférico de pacientes com AR, comparado com indivíduos normais (doadores de TCTH alogênicas), mos- 
trou um aumento global de células T, B e monócitos e de células mielóides anormais $\left(\mathrm{CD} 14^{+} \mathrm{CD} 15^{+}\right)$, a lado de uma diminuição de $\mathrm{CTH}\left(\mathrm{CD} 34^{+}\right)$. Entretanto, essas $\mathrm{CTH}$, frescas ou criopreservadas, apresentavam função hematopoética in vitro similar à dos controles sadios e as células $\mathrm{T}$, coletadas na vigência do tratamento com G-CSF, mostravam reduzida ativação com mitógenos. Esses dados justificam o uso das CTH coletadas do sangue periférico em transplantes autólogos na $\mathrm{AR}^{(45)}$. Por outro lado, um estudo europeu com pacientes com AR candidatos a TCTH mostrou, ao lado de reduzido número de progenitores hematopoéticos na medula óssea dos pacientes, também uma redução da função hematopoética e aumento da apoptose nas células progenitoras mais primitivas. Esses dados, ao contrário do estudo anterior, são preditivos de dificuldades de mobilização e enxertia em pacientes com AR submetidos a TCTH autó$\operatorname{logo}{ }^{(46)}$. 2) No segundo estudo, foram comparadas as doses de 5 e $10 \mu \mathrm{g} / \mathrm{kg} / \mathrm{d}$ de G-CSF, isoladamente, para mobilização de CTH. A dose maior de G-CSF foi associada com maior freqüência de reativação da $\mathrm{AR}$, mas foi escolhida para futuros estudos em decorrência de sua maior eficiência $^{(47)}$. 3) Um outro estudo comparou doses de 100 e $200 \mathrm{mg} / \mathrm{kg}$ de CY, também isoladamente, para o condicionamento de pacientes submetidos a TCTH não manipulado. A dose maior foi associada com um maior período de neutropenia (7 vs. 11 dias) e menor nadir de contagem de plaquetas (16 vs. $\left.143 \times 10^{3} / \mu \mathrm{l}\right)$, mas foi escolhida para futuros estudos porque induziu uma resposta clínica mais prolongada (17-19 vs. 2-3 meses) ${ }^{(48)}$. 4) Finalmente, um estudo recente com 33 pacientes mostrou que a seleção in vitro de $\mathrm{CTH}$ não ofereceu vantagens em relação aos transplantes não-manipulados; ao contrário, esses resultaram em maior freqüência (53 vs. 28\%) e duração (201 vs. 154 dias) de resposta clínica, embora essas diferenças não tenham alcançado significância estatística ${ }^{(49)}$.

\section{ARTRITE IDIOPÁTICA JUVENIL (AIJ)}

Mais de cinqüenta pacientes com as formas sistêmica ou poliarticular da AIJ submetidos a TCTH foram relatados ao registro europeu ${ }^{(10)}$. A evolução a longo prazo (de 8 a 60 meses, com média de 29 meses) de 34 dessas crianças (28 com a forma sistêmica e seis com a forma poliarticular), transplantadas em nove centros europeus, foi recentemente analisada ${ }^{(50,51)}$. A maioria desses pacientes foi transplantada na Holanda e receberam condicionamento com ciclofosfamida $(200 \mathrm{mg} / \mathrm{kg})$, TBI (400cGy) e ATG. Desses pacientes, 18 (53\%) obtiveram remissão clínico-laboratorial completa e duradoura com descontinuação da terapia, incluindo sete crianças com a forma sistêmica de AIJ que foram refratárias a agentes anti-TNF ${ }^{(51)}$. Entretanto, duas dessas crianças apresentaram sinovite transitória dos joelhos e quadris após quadros infecciosos (erupção por H. zoster e amidalite bacteriana $)^{(50)}$ e outras três apresentaram reativação da doença três a seis meses após o transplante, facilmente controlada com antiinflamatórios esteroidais ou não-esteroidais. Evolução semelhante foi apresentada por seis pacientes que mostraram resposta parcial ao TCTH e melhoraram com a terapia antiinflamatória. Por outro lado, sete pacientes (21\%) foram resistentes ao TCTH e foram tratados com altas doses de imunossupressores; dois desses pacientes morreram de infecção 13 e 15 meses após o transplante. Ocorreram três outros óbitos causados pela síndrome de ativação macrofágica (SAM) associada a infecções (uma pelo vírus EpsteinBarr, outra provavelmente bacteriana, na fase de aplasia e uma outra por toxoplasmose disseminada). Crianças de baixa idade que responderam ao TCTH recuperaram o crescimento perdido com a doença, mas isto não ocorreu com as crianças de maior idade ${ }^{(50)}$.

A SAM, também denominada linfo-histiocitose hemofagocítica, parece ser causada por uma deficiência de expressão de perforinas em linfócitos $\mathrm{T}$ e NK, dificultando o controle de doenças infecciosas e da ativação macrofágica na AIJ, particularmente após o TCTH. Este, quando bem sucedido, restaura os níveis de perforina, a função citotóxica ${ }^{(52)}$ e a secreção das proteínas de ativação mielóide MRP-8 e $-14^{(53)}$. Modificações recentes no protocolo do TCTH para AIJ, evitando transplantar pacientes em atividade, tratando-os previamente com pulso de metilprednisolona, têm reduzido drasticamente a incidência da SAM póstransplante ${ }^{(10,11,50)}$. Paralelamente, nos novos protocolos, além do tratamento precoce das infecções, será feita monitorização molecular da infecção por EBV, profilaxia anti-viral com aciclovir e anti-pneumocistose com pentamidina e administração de imunoglobulina EV até o número de linfócitos CD4 se normalizarem ${ }^{(51)}$.

Há evidências, nos dados do registro europeu, de que os regimes de condicionamento empregando irradiação corporal total não são superiores aos regimes que usam apenas quimio ou imunoterapia ${ }^{(10,51)}$, aconselhando a eliminação da radioterapia de futuros protocolos de TCTH para AIJ. Entretanto, um novo regime de condicionamento, usando ciclofosfamida, fludarabina e ATG produziu em 75\% dos pacientes a síndrome de ativação macrofágica ou de hematofagocitose, que foi tratada com sucesso com metilprednisolona e ciclosporina ${ }^{(54)}$. Este fato levou à adoção do regime com ciclofosfamida e ATG para futuros transplantes em AIJ. 
Similarmente ao encontrado na AR do adulto ${ }^{(40,43)}$, também na AIJ foi observada correlação entre o grau de inflamação sinovial com a resposta clínica ao TCTH autólogo e com a redução da expressão local de citocinas pró-inflamatórias ${ }^{(55)}$ e foi sugerida uma maior eficácia do transplante alogênico em relação ao autólogo para induzir remissão da doença $^{(56)}$. De fato, uma criança com forma sistêmica de AIJ recebeu TMO mieloablativo de seu irmão HLA-idêntico, na Hungria, após condicionamento com bussulfano, ciclofosfamida e ATG, produzindo remissão clínica e laboratorial da doença, num seguimento curto (70 dias).

\section{ESCLEROSE SISTÊMICA}

Setenta e dois pacientes registrados no consórcio europeu receberam, em sua maioria, CTH selecionadas in vitro, após condicionamento com ciclofosfamida, com ou sem $\mathrm{ATG}^{(10)}$. Uma análise mais detalhada de 37 pacientes com doença difusa e seguimento superior a três meses incluiu nove pacientes transplantados pelo grupo de Seattle utilizando condicionamento com Cy+ATG+TBI (800cGy). A mortalidade relacionada ao transplante foi de $17 \%$ (sete pacientes) e a relacionada à progressão da doença foi de 10\% (quatro pacientes). Em 29 pacientes analisados mais detalhadamente, através do índice cutâneo de Rodnan e da difusão pulmonar de CO, a doença cutânea melhorou em 70\% (20/29), enquanto a pneumopatia estabilizou-se na metade dos pacientes, melhorou em $10 \%$ e progrediu em $40 \%{ }^{(57)}$. Um seguimento mais longo (>6 meses) de 57 pacientes transplantados na Europa mostrou mortalidade total de $23 \%$ (9\% por complicações do ТСТH e $14 \%$ por progressão da doença), resposta completa em $28 \%$ dos pacientes, parcial em $64 \%$ e $35 \%$ de recaídas ${ }^{(58)}$. Quando 19 pacientes do consórcio de Seattle foram analisados em conjunto, em outro estudo, observou-se a ocorrência de quatro óbitos (três por complicações do transplante: pneumonia intersticial pós-radioterapia [2] e linfoma-EBV ${ }^{+}$associado a doses altas de ATG de coelho [1] e um por progressão da doença). Por outro lado, houve melhora significativa do índice de Rodney para doença cutânea e de escalas de qualidade vida, após um ano, em todos os sobreviventes. A função pulmonar, medida pela difusão de CO, diminuiu após três meses do transplante, recuperando-se após um ano e não progredindo posteriormente na maioria dos pacientes; entretanto, dois pacientes desenvolveram doença pulmonar um e três anos após o transplante, necessitando de tratamento $^{(59)}$. Em um estudo multicêntrico francês com 11 pacientes, condicionados com ciclofosfamida ou melfalan, de acordo com a função cardíaca, oito pacientes tiveram uma resposta inicial (seis completas, duas parciais), mas cinco deles recaíram no período de um ano pós-transplante e dois responderam novamente à imunossupressão convencional. A falha de resposta ou a ocorrência de recaída foram responsáveis por quatro óbitos em 18 meses de seguimento ${ }^{(60)}$.

Os resultados relativamente limitados do TCTH autólogo para formas sistêmicas da ES, principalmente pulmonar, levaram à procura de esquemas mais agressivos de tratamento. Em Seattle, duas pacientes com pneumopatia grave receberam transplante de medula óssea alogênico mieloablativo. Ambas apresentaram resposta clínica, mas uma delas teve uma sepse fatal por Pseudomonas 18 meses após o transplante ${ }^{(61)}$. Em Chicago, um paciente recebeu um TCTH alogênico subablativo e apresentou melhora progressiva da doença cutânea, com quimerismo completo do doador, sem GVHD ou complicações infecciosas ${ }^{(21)}$. Do mesmo modo, em uma criança transplantada recentemente em Israel com CTH autólogas selecionadas in vitro e condicionada com um esquema mieloablativo (BEAM: BCNU, etoposide, citarabina ou ara-C e melfalan), houve dramático desaparecimento da calcinose difusa que a acometia como conseqüência de DAI multissistêmica indiferenciada ${ }^{(62)}$ (Tabela 4).

O recém-iniciado estudo randomizado europeu (ASTIS trial) usa um critério mais estrito de seleção, excluindo comprometimento pulmonar e cardíaco graves, e compara TCTH autólogo (usando ciclofosfamida mais ATG de coelho no condicionamento) com pulsos mensais de ciclofosfamida, tendo sido incluídos, até julho de 2005, 55 pacientes (30 no grupo controle, recebendo pulsos de ciclofosfamida e 25 no grupo de TCTH) sem ocorrência de óbitos em nenhum dos dois grupos (ver site $w w w$.astistrial.com). Como relatado no site, resultados animadores obtidos com os primeiros 20 pacientes levaram à extensão do estudo para pacientes com esclerodermia difusa precoce com marcadores de mau prognóstico. Protocolos semelhantes, patrocinados pelo NIH, foram planejados nos EUA, mas não há consenso entre os vários grupos sobre o melhor regime de condicionamento (com ou sem irradiação corporal total) $)^{(64)}$.

\section{VASCULITES E OUTRAS DOENÇAS REUMÁTICAS}

Várias outras doenças reumáticas, além das mencionadas acima, têm sido tratadas com TCTH autólogo, seja na forma de casos isolados, seja em protocolos clínicos de fases I/II. Assim, o registro europeu contém casos de artrite psoriásica, 
dermatopolimiosite, doença mista do tecido conjuntivo, espondilite anquilosante, síndrome de Sjögren e vasculites $^{(10,11)}$. Entre estas últimas ${ }^{(65)}$, foram transplantadas granulomatose de Wegener (três casos, duas recaídas), crioglobulinemia (três casos, duas respostas completas), poliarterite nodosa (um caso de resposta completa) e doença de Behçet (quatro casos, sendo dois com manifestações pulmonares, evoluindo com resposta completa ou parcial em Heidelberg ${ }^{(66)}$ e um que apresentou recidiva ao TCTH autólogo e ao infliximabe pós-transplante, em Gênova, e foi tratado com transplante alogênico subablativo, também obtendo remissão da doença) (Tabela 4) ${ }^{(67)}$. Recentemente, dois pacientes com doença de Behçet concomitante a síndrome mielodisplásica obtiveram remissão de ambas as doenças com transplante alogênico mieloablativo de células do cordão umbilical ${ }^{(6,688)}$ e outra, com grave envolvimento intestinal pela doença, obteve remissão completa e duradoura (dois anos de evolução) com TCTH autólogo, na Itália ${ }^{(69)}$. Além dos casos mencionados acima de doença de Behçet, o grupo da Universidade de Heidelberg relatou também os transplantes de um paciente com poliarterite nodosa, que obteve remissão completa duradoura e de outro com vasculite indiferenciada, com resposta parcial; um terceiro paciente, com vasculite $\mathrm{ANCA}^{+}$, recuperou-se completamente após a mobilização com $4 \mathrm{~g} / \mathrm{m}^{2}$ de ciclofosfamida e não foi transplantado ${ }^{(65)}$. Em adição, o grupo da Universidade de Birmingham relatou o transplante de dois pacientes com granulomatose de Wegener, ocorrendo recaída em ambos, dois e três anos após o transplante ${ }^{(70)}$ e, na Áustria, uma criança de oito anos de idade com granulomatose de Wegener associada a p-ANCA recebeu um TMO submieloablativo de seu irmão HLA-idêntico; desenvolveu hepatopatia, trombocitopenia e GVHD crônico de pele, que responderam a esplenectomia e corticoesteróide oral e obteve remissão da vasculite, voltando a estudar ${ }^{(71)}$. Curiosamente, em uma paciente que recebeu TCTH autólogo para poliarterite nodosa juvenil em Londres, Reino Unido, apesar de a doença ter entrado em remissão após 18 meses de seguimento, surgiram outras DAIs após o transplante (vasculite cutânea, doença de Graves e púrpura trombocitopênica auto-imune), que foram controladas com tratamento adequado ${ }^{(72)}$. Por outro lado, uma paciente de 13 anos de idade, portadora de uma síndrome de superposição auto-imune, com vasculite pulmonar, entrou em remissão com um transplante alogênico não-mieloablativo combinado de medula óssea, espículas ósseas e osteoblastos cultivados in vitro, após um condicionamento também subablativo $^{(73)}$.
O banco de dados do EBMT/Eular, na Basiléia, possui registros de sete pacientes portadores de polimiosite/dermatopolimiosite submetidos a TCTH autólogo, com apenas uma resposta completa, três respostas parciais e um óbito por toxicidade à ATG no condicionamento (Tyndall, comunicação pessoal). Em relatos de casos individuais, um paciente com polimiosite associada ao anticorpo Jo-1 foi transplantado com sucesso na Bélgica ${ }^{(74)}$, enquanto outro na Inglaterra teve recidiva precoce, obtendo resposta parcial com reintrodução da imunossupressão (metotrexato e cicloporina) ${ }^{(75)}$; está em remissão, atualmente, após ter se recuperado de uma micobacteriose atípica (Bingham, comunicação pessoal). Similarmente, um paciente com miosite grave associada a doença mista do tecido conjuntivo, apesar de melhora subjetiva e remissão laboratorial logo após o transplante, teve recidiva da miosite no seguimento a longo prazo $(21 \text { meses })^{(76)}$. Finalmente, um paciente com policondrite recidivante obteve remissão completa e duradoura após TCTH autólogo realizado na Finlândia ${ }^{(77)}$, o mesmo acontecendo com outro paciente, portador de síndrome de Sjögren, transplantado em Trieste, Itália, e que continua recebendo azatioprina após o transplante (Rabusin, comunicação pessoal) (Tabela 4).

Citopenias hematológicas auto-imunes, associadas ou não a doenças reumáticas, têm sido transplantadas com CTH, com relativo sucesso ( $30 \%$ a $50 \%$ de remissão completa), nos Estados Unidos ${ }^{(78)}$ e na Europa ${ }^{(79)}$. Assim, na experiência do NIH, 6/14 pacientes com trombocitopenia auto-imune crônica tiveram resposta completa ao TCTH autólogo e dois tiveram resposta parcial, sem ter ocorrido nenhum óbito(78). Um estudo recente do grupo europeu de TMO $(\text { EBMT })^{(69)}$ analisou a evolução de 36 pacientes submetidos a TCTH autólogo $(\mathrm{N}=27)$ ou alogênico $(\mathrm{N}=9)$ para citopenias auto-imunes. Surpreendentemente, os transplantes alogênicos resultaram em menor mortalidade (1/9) do que os autólogos $(4 / 27)$, além de produzirem mais remissões completas (5/9 vs. 9/27). O estudo não incluiu pacientes com citopenias secundárias a doenças reumáticas, como o LES. Neste último subgrupo de pacientes, analisado em outro trabalho ${ }^{(24)}$, citopenias hematológicas ocorreram em 55\% (29/53) dos pacientes lúpicos, revertendo, na metade deles, após a mobilização e, na maioria dos restantes, três meses após o TCTH. Entretanto, um grande número de pacientes continuou a receber imunossupressão, principalmente MMF (dez com trombocitopenia e sete com leucopenia) para manter o efeito terapêutico (Jayne, comunicação pessoal). Como mostrado em dois pacientes do estudo anterior ${ }^{(69)} \mathrm{e}$ em relatos esporádicos de casos, algumas 
vezes é necessário recorrer a um transplante alogênico quando o transplante autólogo falha em induzir remissão da doença ${ }^{(80)}$ ou à infusão de linfócitos alogênicos, quando ocorre recaída após o transplante alogênico ${ }^{(81)}$.

\section{CONCLUSÕES}

A experiência internacional com várias centenas de pacientes transplantados para doenças reumáticas graves e refratárias à terapia convencional, em protocolos de fase I e II, revelou o potencial desta terapia para induzir remissão prolongada na maioria desses pacientes, com a notável exceção da artrite reumatóide do adulto. A toxicidade e a mortalidade do procedimento ainda é significativa, principalmente para pacientes com LES e ES afetados por disfunções importantes de órgãos vitais, como os pulmões e os rins. Ainda assim, esses resultados são encorajadores, dado o mau prognóstico da maioria dos pacientes transplantados,

\section{REFERÊNCIAS}

1. Pincus T, Callahan LF: Remodeling the pyramid or remodeling the paradigms concerning rheumatoid arthritis - Lessons from Hodgkin's disease and coronary artery disease. J Rheumatol 17: 1582-85, 1990.

2. Van Bekkum DW: Preclinical experiments. Best Practice \& Res Clin Haematol 17: 201-22, 2004.

3. Shizuru JA: The experimental basis for hematopoietic stem cell transplantation for autoimmune diseases. Em: “Thomas' Hematopoietic cell transplantation," ed. por KG Blume, SJ Forman, FR Appelbaum, 3.a ed, Malden, MA, EUA, Blackwell Publishing Inc, 2004, p. 324-43.

4. Good RA, Verjee T: Historical and current perspectives on bone marrow transplantation for prevention and treatment of immunodeficiencies and autoimmunities. Biol Blood Marrow Transplant 7: 123-35, 2001.

5. Moore J, Tyndall A, Brooks P: Stem cells in the aetiopathogenesis and therapy of rheumatic diseases. Best Practice Res Clin Rheumatol 15: 711-26, 2001.

6. Marmont A: Coincidental aoutoimmune disease in patients transplanted for conventional indications. Best Practice Res Clin Haematol 17: 223-32, 2004.

7. Nelson L, Torrez R, Louie FM, et al: Pre-existing autoimmune disease in patients with longterm survival after allogeneic bone marrow transplantation. J Rheumatol (Supl 48) 24: 23-9, 1977.

8. Marmont AM: New horizons in the treatment of autoimmune disease: Immunoablation and stem cell transplantation. Ann Rev Med 51:115-34, 2000.

9. Bingham SH, Snowden J, Morgan G, et al: High dose immunosuppressive therapy and stem cell transplantation in autoimmune and inflammatory diseases. Int Immunopharmacol 2: 399-414, 2002.

10. Tyndall A, Gratwohl A: Hematopoietic stem cell transplantation for autoimmune diseases. Em: “Thomas' Hematopoietic cell transplantation,” ed. por KG Blume, SJ Forman, FR Appelbaum, 3.a ed, Malden, MA, EUA, Blackwell Publishing Inc, 2004, p. 1385-93. e autorizaram o início de protocolos prospectivos randomizados, nos países desenvolvidos, comparando o TCTH com a melhor terapia convencional disponível. O protocolo europeu para esclerose sistêmica (Astistrial) é o mais avançado nesse sentido, já tendo incluído 55 pacientes.

$\mathrm{Na}$ segunda parte desta revisão, serão analisados os resultados dos TCTH para doenças reumáticas realizados no Brasil, as questões científicas pendentes nesta área e as perspectivas futuras de seu desenvolvimento.

\section{AGRADECIMENTOS}

Aos Drs. Alan Tyndall (Basiléia, Suíça), David Jayne (Cambridge, Inglaterra), Sarah Bingham (Leeds, Inglaterra), Marco Rabusin (Trieste, Itália) e Richard Burt (Chicago, EUA), por fornecerem informações não publicadas, e à Fapesp, CNPq, Finep, FUNDHERP-Hemocentro-RP e FAEPA-HCFMRP-USP pelo apoio financeiro.

11. Gratwohl A, Passweg J, Gerber I, Tyndall A: Stem cell transplantation for autoimmune diseases. Best Practice Res Clin Haematol 14: 755-76, 2002.

11a. Gratwohl A, Passweg J, Bocelli-Tyndall C, et al: Autologous hematopoietic stem cell transplantation for autoimmune diseases. Bone Marrow Transplant 35: 869-79, 2005.

11b. Tyndall A, Saccardi R: Hematopoietic stem cell transplantation in the treatment of severe autoimmune disease: results from phase I/II studies, prospective randomized trials and future directions. Clin Exp Immunol 141: 1-9, 2005.

12. Burt RK, Slavin S, Burns WH, Marmont A: Induction of tolerance in autoimmune diseases by hematopoietic stem cell transplantation: Getting closer to a cure? Blood 99: 768-84, 2002.

13. Furst DE: Stem cell transplantation for autoimmune disease: progress and problems. Curr Opin Rheumatol 14: 220-4, 2002.

14. Slavin S: Treatment of life-threatening autoimmune diseases with myeloablative doses of immunosuppressive agents: experimental background and rationale for ABMT. Bone Marrow Transplant 12: 85-8, 1993.

15. Brodsky RA, Petri M, Smith B, et al: Immunoablative high dose cyclophosphamide without stem cell rescue for refractory, severe autoimmune disease. Ann Intern Med 129: 1031-5, 1998.

16. Petri M, Jones RJ, Brodsky RA: High-dose cyclophosphamide without stem cell transplantation in systemic lupus erythematosus. Arthritis Rheum 48: 166-73, 2003.

17. Tisdale JF, Dunn DE, Geller N, et al: High-dose cyclophosphamide in severe aplastic anemia: a randomised trial. Lancet 356: 1554-9, 2000.

18. Tamm M, Gratwohl A, Tichelli A, et al: Autologous haemopoietic stem cell transplantation in a patient with severe pulmonary hypertension complicating connective tissue disease. Ann Rheum Dis 55: 779-80, 1996.

19. Marmont AM: Lupus: tinkering with stem cells. Lupus 10: 769-74, 2001. 
20. Ferreira E, Ribeiro A, Bacal NS, et al: Transplante de células-tronco periféricas autólogas no tratamento de doença auto-imune: remissão completa da anemia hemolítica por aglutinina a frio e concomitante vasculite. Bol Soc Bras Hematol Hemoter 18 (supl): 191-O, 1996.

21. Burt RK, Verda L, Oyama Y, et al: Non-myeloablative stem cell transplantation for autoimmune diseases. Springer Seminars Immunopathol 26: 57-69, 2004.

22. Voltarelli JC: Hematopoietic stem cell transplantation for autoimmune diseases in Brazil: Current status and future prospectives. Rev Bras Hematol Hemoter 24: 206-11, 2002.

23. Voltarelli JC, Ouyang J: Hematopoietic stem cell transplantation for autoimmune diseases in developing countries: Current status and future prospectives. Bone Marrow Transplant, in press, 2005.

24. Jayme D, Passweg J, Marmont A, et al: Autologous stem cell transplantation for systemic lupus erythematosus. Lupus 13: 168-76, 2004.

25. Traynor A, Barr WG, Rosa RM, et al: Hematopoietic stem cell transplantation for severe and refractory lupus. Analysis after five years and fifteen patients. Arthritis Rheum 40: 2917-23, 2002.

25a. Burt RK, Oyama Y, Statkute L, et al: Autologous nonmyeloablative hematopoietic stem cell transplantation for severe systemic lupus erythematosus. Blood 104: 46a, 2004.

26. Statkute L, Traynor A, Oyama Y, Yaung RN, Verda L, Burt RK: Antiphospholipid syndrome in patients with systemic lupus erythematosus treated by autologous hematopoietic stem cell transplantation. Blood, in press, 2005.

27. Olalla JI, Ortín M, Hermida G, et al: Disappearance of lupus anticoagulant after allogeneic bone marrow transplantation. Bone Marrow Transplant 23: 83-5, 1999.

28. Wahlin A: Unrelated allogeneic stem cell transplant with reduced intensity conditioning in a patient with antiphospholipid syndrome and Evans syndrome. Bone Marrow Transplant 29 (Suppl 2): S105-6, 2002.

29. 29. Hashimoto N, Iwasaki T, Sekiguchi M, et al: Autologous hematopoietic stem cell transplantation for refractory antiphospholipid syndrome causing myocardial necrosis. Bone Marrow Transplant 33: 863-6, 2004.

29a. Verburg RJ, Sont JK, Van Laar JM: Reduction of joint damage in severe rheumatoid arthrtiris by high-dose chemotherapy and autologous stem cell transplantation. Arthritis Rheum 52: 421-4, 2005.

29b. Teng YK, Verburg RJ, Sont JK, et al: Long term followup of health status in patients with severe rheumatoid arthritis after high-dose chemotherapy followed by autologous hematopoietic stem cell transplantation. Arthritis Rheum 52: 2272-6, 2005.

30. Brunner M, Greinix HT, Redlich K, et al: Autologous blood stem cell transplantation in refractory systemic lupus eryrthematosus with severe pulmonary impairment: a case report. Arthritis Rheum 46: 1580-4, 2002.

31. Trysberg E, Lindgren I, Tarkowski A: Autologous stem cell transplantation in a case of treatment resistant central nervous system lupus. Ann Rheum Dis 59: 236-8, 2000.

32. Jian O-Y, Bing C, Cuiping Y: A pilot study in treatment of severe SLE relapsing after ABMT by purified peripheral blood CD34 ${ }^{+}$cells transplantation in China. Bone Marrow Transplant 31 (Suppl 1): S99, 2003.

33. Zhao J, Fu Y, Peng X: Autologous hematopoietic stem cell transplantation in the treatment of systemic lupus erythematosus. Bone Marrow Transplant 29 (Suppl 2): S15, 2002.
34. Chen J, Gu L-J, Xue H-L, et al: Primary report on the application of CD34+ autologous peripheral blood progenitor cell transplantation in the treatment of children with refractory systemic lupus erythematosus (SLE). Blood (Supl 1): 475b, 2002.

35. Lisukov IA, Sizikova AS, Kulagin AD, et al: High dose immunosuppression with autologous stem cell transplantation in severe refractory systemic lupus erythematosus. Lupus 13: 89-94, 2004.

36. Burt RK, Marmont A, Arnold R, et al: Development of a phase III trial of hematopoietic stem cell transplantation for systemic lupus erythematosus. Bone Marrow Transplant 32: 549-51, 2003.

37. Snowden JA, Passweg J, Moore JJ, et al: Autologous hemopoietic stem cell transplantation in severe rheumatoid arthritis: A report from the EBMT and ABMTR. J Rheumatol 31: 482-8, 2004.

38. Pavletic SZ, Klassen LW, Pope R, et al: Treatment of relapse after autologous blood stem cell transplantation for severe rheumatoid arthritis. J Rheumatol 28 (Suppl 64): 28-21, 2001.

39. Moore J, Ma D, Will R, et al: A phase II study of Rituximab in Rheumatoi arthritis patients with recurrent disease following hematopoietic stem cell transplantation. Bone Marrow Transplant 34: 241-7, 2004.

40. Bingham S, Veale D, Fearon U, et al: High dose cyclophosphamide with stem cell rescue for severe rheumatoid arthritis: short term efficacy correlates with reduction of macroscopic and histologic synovitis. Arthritis Rheum 46: 837-9, 2002.

40a. Verburg R, Flierman R, Sont J, et al: The outcome of intensive immunosuppression and autologous stem cell transplantation in patients with severe rheumatoid arthritis is associated with the composition of synovial T cell infiltration. Ann Rheum Dis, in press, 2005.

41. Espigado I, Garcia A, Rodriguez JM, et al: Hemopoietic stem cell transplantation in refractory rheumatoid arthritis is not a contraindication for reconstructive surgery. Clin Exp Rheumatol 21: 643-4, 2003.

42. Burt RK, Georganas C, Schroeder J, et al: Autologous hematopoietic stem cell transplantation in refractory rheumatoid arthritis: sustained response in two of four patients. Arthritis Rheum 42: 2281-5, 1999.

43. Burt RK, Oyama Y, Verda L, et al: Induction of remission of severe and refractory rheumatoid arthritis by allogeneic mixed chimerism. Arthritis Rheum 50: 2466-70, 2004.

44. Tapprich C, Fenk R, Schneider P, et al: Early recurrence of rheumatoid arthritis after nonmyeloablative allogeneic blood stem cell transplantation in a patient with multiple myeloma. Bone Marrow Transplant 32: 629-31, 2003.

45. Snowden JA, Nink V, Cooley M, et al: Composition and function of peripheral blood stem and progenitor cell harvests from patients with severe active rheumatoid arthritis. Br J Haematol 103: 601-9, 1998.

46. Porta C, Caporali R, Epis O, et al: Impaired bone marrow hematopoietic progenitor cell function in rheumatoid arthritis patients candidated to autologous hematopoietic stem cell transplantation. Bone Marrow Transplant 33: 721-8, 2004.

47. Snowden JA, Biggs JC, Milliken ST, et al: A randomised, blinded, placebo-controlled, dose scalation study of the tolerability and efficacy of filgrastrim for haematopoietic stem cell mobilisation in patients with severe active rheumatoid arthritis. Bone Marrow Transplant 22: 1035-41, 1998.

48. Snowden JA, Biggs JC, Milliken ST, et al: A phase I/II dose escalation study of intensified cyclophosphamide and autologous blood stem 
cell rescue in severe, active rheumatoid arthritis. Arthritis Rheum 42: 2286-92, 1999

49. Moore J, Brooks P, Milliken S, et al: A pilot randomized trial comparing CD34-selected versus unmanipulated hemopoietic stem cell transplantation for severe, refractory rheumatoid arthritis. Arthritis Rheum 46: 2301-9, 2002.

50. Wulffraat NM, Brinkman D, Ferster A, et al: Long-term follow-up of autologous stem cell transplnatation for refractory juvenile idiopathic arthritis. Bone Marrow Transplant 32: 561-4, 2003.

51. De Kleer IM, Brinkman DMC, Ferster A, et al: Autologous stem cell transplantation for refractory juvenile idiopathic arthritis: Analysis of clinical effects, mortality, and transplant related mortality. Ann Rheum Dis 63: 1318-26, 2004.

52. Wulfraat NM, Rijkers GT, Elst E, et al: Reduced perforin expression in systemic juvenile idiopathic arthritis is restored by autologous stem-cell transplantation. Rheumatology 42: 375-9, 2003.

53. Wulfraat NM, Haas PJ, Frosch M, et al: Myeloid related protein 8 and 14 secretion reflects phagocyte activation and correlates with disease activity in juvenile idiopathic arthritis treated with autologous stem cell transplantation. Ann Rheum Dis 62: 236-41, 2003.

54. Wulffraat N, Van Royen-Kerkhof A, Abinun M, et al: Three cases of haemophagocytosis (MAS) during SCT for systemic juvenile idiopathic arthritis, possibly caused by fludarabin. Bone Marrow Transplant 33 (Suppl 1): S144-5, 2004.

55. Brinkman DMC, Tem Cate R, Vossen JM, et al: Decrease in synovial cellularity and cytokine expression after autologous stem cell transplantation in patients with juvenile idiopathic arthritis. Arthritis Rheum 46: 1121-3, 2002.

56. Nagy K, Vertesi G, Marton G, et al: Allogenic HLA identical bone marrow transplantation in patient with juvenile idiopathic/chronic/ arthritis/JIA. Bone Marrow Transplant 33 (Suppl 1): S 146, 2004.

57. Binks M, Passweg JR, Furst D, et al: Stabilization or improvement of progressive skin disease in scleroderma following autologous hematopoietic stem cell transplantation. Ann Rheum Dis 60: 577-84, 2001.

58. Farge D, Passweg J, Van Laar JM, et al: Autologous stem cell transplantation in the treatment of systemic sclerosis: report from EBMT/EULAR registry. Ann Rheum Dis 63: 974-81, 2004.

59. McSweeney PA, Nash RA, Sullivan KM, et al: High dose immunosuppressive therapy for severe systemic sclerosis: initial outcome. Blood 100: 1602-10, 2002.

60. Farge D, Marolleau JP, Zohar S, et al: Autologous bone marrow transplantation in the treatment of refractory systemic sclerosis: early results from a French multicentre phase I-II study. Br J Haematol 119: 726-39, 2002.

61. Nash RA, McSweeney PA, Storb R, et al: Treatment of severe systemic sclerosis with allogeneic marrow transplantation. Blood (Suppl): 98: 460b, 2001.

62. Elhasid R, Rowe JM, Berkowitz D, Bem-Arush M, Bar-Shalom R, Brik R: Disappearance of diffuse calcinosis following autologous stem cell transplantation in a child with autoimmune disease. Bone Marrow Transplant 33: 1257-9, 2004.

63. Farge D, Van Laar JM, Tyndall A: The European randomized HSCT trial for scleroderma. Blood \& Marrow Transplant Rev 14: 7-9, 2004.

64. Burt RK, Kallunian K, Patel D, et al: The rationale behind autologous autoimmune hematopoietic stem cell transplant conditioning regimens: concerns over the use of total body irradiation in systemic sclerosis. Bone Marrow Transplant 34: 745-51, 2004

65. Fiehn C, Hensel M: High dose chemotherapy with haematopoietic stem cell transplantation in primary systemic vasculitis, Behçet's diseases and Sjögren's syndrome. In "Stem cell therapy for autoimmune diseases", edited by RK Burt \& A Marmont, Landes Bioscience, Georgetown, TX, USA, 411-8, 2003.

66. Hensel M, Breitbart A, Ho AD: Autologous hematopoietic stem cell transplantation for Behçet's disease with pulmonary involvement. New Engl J Med 344: 69, 2001.

67. Gualandi F, Raiola AM, Dominieto A, et al: Allogeneic BMT for refractory Behçet's disease having relapsed following ABMT. Bone Marrow Transplant 33 (Suppl 1): S346, 2004.

68. Yamato K: Successful cord blood stem cell transplantation for myelodiysplastic syndrome with Behçet disease. Int J Hematol 77: 82-5, 2003.

68a. Tomonari A, Tojo A, Takahashi T, et al: Resolution of Behçet's disease after HLA-mismatched unrelated cord blood transplantation for myelodisplastic syndrome. Ann Hematol 83: 464-6, 2003.

69. Rossi G, Moretta A, Locatelli F: Autologous hematopoietic stem cell transplantation for severe/refractory intestinal Behcet disease. Blood 103: 748-50, 2004.

70. Bacon PA, Bchir MB: New therapeutic aspects: haemopoietic stem cell transplantation. Best Practice \& Research Clin Rheumatol 2: 299-313, 2001.

71. Lawitschka A, Matthes-Martin S, Holter W, et al: P-ANCA associated vasculitis (M. Wegener): susscessful HLA-identical BMT. Bone Marrow Transplant 29 (Suppl 2): S106, 2002.

72. Wedderburn LR, Jeffery R, White H, et al: Autologous stem cell transplantation for paediatric-onset polyarteritis nodosa: changes in autoimmune phenotype in the context of reduced diversity of the $\mathrm{T}$-and $\mathrm{B}$-cell repertoires, and evidence for reversion from the $\mathrm{CD} 4 \mathrm{RO}^{+}$to $\mathrm{RA}^{+}$phenotype. Rheumatology 40: 1299-307, 2001.

73. Jones OY, Good RA, Cahill RA: Nonmyeloablative allogeneic bone marrow transplantation for treatment of childhood overlap syndrome and small vessel vasculitis. Bone Marrow Transplant 33: 1061-3, 2004.

74. Baron F, Ribbens C, Jaye O, et al: Effective treatment of Jo-1 associated polymyositis with T-cell-depleted autologous peripheral blood stem cell transplantation. Br J Haematol 110: 339-42, 2000.

75. Bingham S, Griffiths B, McGonagle D, et al: Autologous SCT for rapidly progressive Jo-1 positive polymyositis with long term followup. Br J Haeamatol 113: 840-1, 2001.

76. Myllykangas-Luosujarvi R, Jantunen E, Kaipiainen-Seppanen O, Mahlamaki E, Nousiainen T: Autologous peripheral bolld stem cell transplantation in a patient with severe mixed connective tissue disease. Scand J Rheumatol 29: 326-7, 2000.

77. Hiepe F, Thiel A, Rosen O, et al: Autologous stem cell transplantation in relapsing polychondritis. Stem Cell therapy for autoimmune disease, edited by RK Burt \& A Marmont, Landes Bioscience, Georgetown, TX, USA, p. 468-473, 2004.

78. Huhn RD, Fogarty PF, Nakamura R, et al: High dose cyclophosphamide with autologous lymphocyte-depleted peripheral blood stem cell (PBSC) support for treatment of refractory chronic autoimmune thrombocytopenia. Blood 101: 71-7, 2003.

79. Passweg JR, Rabusin M, Musso M, et al: Haematopoietic stem cell transplantation for refractory autoimmune cytopenia. British J Haematology 125: 749-55, 2004.

80. Stefano P, Zecca M, Giorgiani G, et al: Resolution of immune haemolytic anaemia with allogeneic bone marrow transplantation after an unsuccessful autograft. Br J Haeamatol 106: 1063-4, 1999.

81. Marmont AM, Gualandi F, Van Lint MT, et al: Refractory Evan's syndrome treated with allogeneic SCT followed by DLI. Demonstration of a graft-versus-autoimmunity effect. Bone Marrow Transplant 31: 399-402, 2003. 